\section{Case Reports in Ophthalmology}

Case Rep Ophthalmol 2020;11:356-363

DOI: $10.1159 / 000508064$

Published online: July 14, 2020
(C) 2020 The Author(s)

Published by S. Karger AG, Basel www.karger.com/cop

This article is licensed under the Creative Commons Attribution-NonCommercial 4.0 International License (CC BY-NC) (http://www.karger.com/Services/OpenAccessLicense). Usage and distribution for commercial purposes requires written permission.

\title{
Spherophakia and Ectopia Lentis in a Sturge-Weber Patient: A Case Report
}

\author{
Samuel Josue Avalos-Lara ${ }^{a}$ Bani Antonio-Aguirre ${ }^{a, b}$ Andric C. \\ Perez-Ortiz ${ }^{c, d} \quad$ Cristina Mendoza Velásquez ${ }^{a}$ Azyadeh \\ Camacho-Ordoñez $^{a} \quad$ Claudia Palacio Pastrana ${ }^{a}$ \\ aDepartment of Microsurgery of the Anterior Segment, Fundación Hospital Nuestra \\ Señora de la Luz IAP, Cuauhtemoc, Mexico; ${ }^{b}$ Department of Molecular Biology and \\ Biochemistry, Universidad Panamericana Escuela de Medicina, Benito Juarez, Mexico; \\ 'Department of Public Health, Universidad Panamericana Escuela de Medicina, Benito \\ Juarez, Mexico; dDepartment of Surgery, Massachusetts General Hospital, \\ Boston, MA, USA
}

\section{Keywords}

Spherophakia · Ectopia lentis · Sturge-Weber syndrome

\begin{abstract}
Sturge-Weber syndrome (SWS) is a rare, sporadic neurocutaneous disorder, primarily characterized by port-wine stain (PWS) over the ophthalmic division of the trigeminal nerve (V1) territory (hallmark feature) and glaucoma (in 30-60\% of cases). Other ocular manifestations include episcleral involvement of the PWS, choroidal vascular malformations, and iris heterochromia. Two previous reports also associated ectopia lentis concomitantly among these cases. However, here we report spherophakia as a novel ophthalmological finding in SWS. A 56-yearold female previously diagnosed with SWS presented to the outpatient clinic complaining of right-sided decreased visual acuity and pain after a fall. Phenotypically, the patient had a PWS around V1 territory and involvement of both eyelids. Previous relevant ocular history included retinal detachment without macular involvement, ocular hypertension, and phacodonesis. The slit-lamp examination showed anterior lens luxation and elevated intraocular pressure (IOP) of $40 \mathrm{~mm} \mathrm{Hg}$ by tonometry. Prior to the surgical approach, the patient received hypotensive
\end{abstract}


treatment for elevated IOP. After intracapsular lens extraction, measurements were consistent with spherophakia. Postoperatively, the patient underwent optical coherence tomography (OCT). There was cystic macular edema (CME) by OCT and a detached posterior hyaloid membrane. The patient fully recovered with topical treatment of bromfenac for CME. To the best of our knowledge, this is the first report of concomitant anterior lens luxation and spherophakia (novel association) in a SWS patient. Our findings supplement the differential ocular diagnoses in SWS and should be considered in the routine ocular exam, specifically of the anterior segment. CME occurred similar to otherwise healthy eyes. However, in this case, topical anti-inflammatory medications had a good response and were well-tolerated.

(C) 2020 The Author(s)

Published by S. Karger AG, Basel

\section{Introduction}

Sturge-Weber syndrome (SWS) is a rare sporadic neurocutaneous disorder caused by a somatic activating mutation in GNAQ in $88 \%$ of the cases [1]. SWS affects 1 in 20,000 live births and it is characterized by a unilateral capillary facial malformation (port-wine stain, PWS) of the skin in the territory of the ophthalmic (V1) and/or maxillary (V2) branch of the trigeminal nerve [2]. Additionally, affected individuals can present abnormal capillary vessel development in the leptomeninges of the choroid and the brain [3]. This atypical vasculature usually leads to multiple neurological and ocular manifestations. Seizures, particularly infantile spasms, develop in $90 \%$ of affected cases during the first year of life. Intellectual disability and stroke-like episodes are also common [4]. In the eye, the dilated tortuous venous vessels in the conjunctiva, episclera, and/or choroid can lead to glaucoma (in $30-60 \%$ of cases) [5]. Other ocular findings are heterochromia iridum, retinal detachment, and phakomatosis pigmentovascularis [5]. To date, there are no reports on lens shape alterations apart from lens luxation in SWS cases.

Spherophakia is a congenital eye disorder, usually bilateral, that presents with increased anteroposterior diameter (a more spherical lens), varying degrees of lenticular myopia, and zonular weakness [6]. Spherophakia can occur isolated, affect multiple family members, or be associated with homocysteinemia, hyperlysinemia, Weil-Marchesani, Marfan, and Alport syndromes [7, 8]. Among affected cases, hypoplastic lens zonules fibers are conducive for lens subluxation or dislocation from the fossa leading to pupillary block glaucoma $[6,9]$.

To the best of our knowledge, there are no reports on the association between spherophakia and SWS. Two case reports suggested an association between SWS and ectopia lentis, one attributable to trauma $[10,11]$. However, lens shape parameters were not reported, and it is unclear whether these cases had a pathologic lens shape that might be conducive for ectopia lentis. Here, we describe a SWS case with a concomitant diagnosis of spherophakia and ectopia lentis.

\section{Case Report}

A 56-year-old woman previously diagnosed with SWS presented to the outpatient clinic complaining of an acute right eye (OD) decrease in visual acuity (VA). The previous medical and family histories of the proband were unremarkable, specifically for collagen disorders. Physical examination was remarkable for a classic PWS in V1 and V2 territory, predominant in V2. The PWS involved part of the upper and lower eyelid (Fig. 1). On exam, the best- 


\section{Case Reports in Ophthalmology}

Case Rep Ophthalmol 2020;11:356-363

DOI: $10.1159 / 000508064$

(c) 2020 The Author(s). Published by S. Karger AG, Basel www.karger.com/cop

Avalos-Lara et al.: Spherophakia and Ectopia Lentis in SWS

corrected visual acuity (BCVA) of the OD was hand motion close to the face with refraction of $-2.75 \mathrm{D}$ sphere. On further evaluation, we evidenced conjunctival hyperemia, increased intraocular pressure (IOP) of $28 \mathrm{~mm} \mathrm{Hg}$, phacodonesis, and retinal detachment without macular involvement, although with subretinal fibrosis at 3-, 9-, and 12-o'clock meridians (Fig. 2). Due to the extensive proliferative vitreoretinopathy and the absence of macular compromise, we performed argon laser treatment. The postoperative VA was 20/40.

One year later, the patient presented to the emergency room with OD pain following low impact trauma. On the OD exam, we observed corneal edema, a dichroic pupil, and an IOP of $40 \mathrm{~mm} \mathrm{Hg}$. The lens was luxated anteriorly and moderately opacified (Lens Opacification System III Grade NO3 NC3) (Fig. 3) [12]. The BCVA of OD was finger counting at $30 \mathrm{~cm}$. We started IOP-lowering treatment with topical timolol $0.5 \%$, dorzolamide $2 \%$, and brimonidine $0.2 \%$ twice daily. Additionally, she received acetazolamide $250 \mathrm{mg}$ orally every $6 \mathrm{~h}$. We achieved IOP control at the end of the first day of treatment and lowered the IOP to $21 \mathrm{~mm} \mathrm{Hg}$.

After achieving IOP control, due to the high risk of expulsive hemorrhage, we performed an intracapsular extraction to address the lens luxation. Prophylactically, we administered intravenous mannitol prior to the procedure. We began with a peritomy and dissected the Tenon's capsule from 8- to 12-o'clock meridians. Thereafter, we cauterized the episcleral vessels and made three scleral incisions at $2 \mathrm{~mm}$ from the sclerocorneal limbus. The space between the lens and the anterior hyaloid was filled with viscoelastic by paracentesis. We then completed the scleral incision and the whole lens was extracted, leaving the case aphakic.

The extracted lens had an equatorial diameter of $8 \mathrm{~mm}$ and an anteroposterior length of $6 \mathrm{~mm}$, based on these findings we diagnosed spherophakia. During the follow-up, the right IOP remained at $16 \mathrm{~mm} \mathrm{Hg}$ without IOP-lowering drugs. However, there was no improvement in VA. We then performed an optical coherence tomography (OCT) and observed cystic macular edema (CME) (macular central thickness of $524 \mu \mathrm{m}$ ) and posterior hyaloid separation (Fig. 4). All these findings were compatible with CME secondary to surgery. The patient received topical bromfenac $0.09 \%$ three times a day for 6 weeks for CME treatment. After treatment, macular central thickness decreased to $220 \mu \mathrm{m}$ and BCVA improved significantly to 20/30 after contact lens rehabilitation. Finally, we performed an ultrasound biomicroscopy exam on the contralateral eye (OS) to rule out spherophakia. The report showed normal lens measurements; an equatorial diameter of $10.7 \mathrm{~mm}$ and the anteroposterior axis of $5 \mathrm{~mm}$ (Fig. 5). Hence, our final diagnosis was unilateral spherophakia (OD) ipsilateral to the PWS.

\section{Discussion/Conclusion}

SWS is a condition with a wide range of ophthalmological manifestations. So far, two reports have proposed an association of SWS and ectopia lentis. Here, we present the third case of ectopia lentis in a SWS patient. Notwithstanding, our comprehensive approach evidenced a plausible cause for ectopia lentis in the spherophakia. Our patient had an abnormal zonule and an abnormally shaped lens; the luxation might be the result of the existing spherophakia added to the low impact trauma. Spherophakia, in our case, was diagnosed after the lens was extracted. However, evidence supports that in the 50-year-old population, in vivo and in vitro lens shape is not significantly different $[13,14]$. Also, we purposefully excluded any family history of the patient that might be conducive for lens luxation such as Ehlers-Danlos, Marfan syndrome, and other collagen disorders. Moreover, by ultrasound biomicroscopy, we ruled out spherophakia in the contralateral eye. All these pieces of evidence led us to suggest that spherophakia is a plausible novel finding in SWS that could favor ectopia lentis. 


\section{Case Reports in Ophthalmology}

Avalos-Lara et al.: Spherophakia and Ectopia Lentis in SWS

Isolated or unilateral spherophakia is rare; rather it is commonly associated with systemic and genetic disorders and typically bilateral [15]. In our patient, spherophakia was unilateral and ipsilateral to the PWS [7]. Most of the ocular manifestations in SWS patients are restricted to the PWS [16]. Hence, the odds of having concomitantly isolated unilateral spherophakia without an association with SWS are low. Previous reports proposed spherophakia as a plausible mechanism of lens luxation $[17,18]$. The round shape of the lens and the loose zonular attachment are conducive for ectopia lentis [8]. However, this field is underdeveloped, and more research is needed to provide further evidence of this mechanism. Finally, after intracapsular lens extraction, a scleral-fixed or sulcus intraocular lens might be an effective treatment. However, our patient had a history of extensive retinal detachment [9]. Hence, we concluded on leaving our case aphakic and started rehabilitation with a contact lens [19].

Altogether, we provide evidence of concomitant occurrence in SWS of spherophakia and ectopia lentis. Our report bolsters the importance of extensive and lifelong monitoring of this population for ocular complications related to SWS, specifically glaucoma or other anterior segment abnormalities. Close monitoring is needed as it might compromise the visual prognosis. Even further, when encountering ectopia lentis in an SWS, we suggest evaluating lens shape for spherophakia.

\section{Statement of Ethics}

Written informed consent was obtained from the patient for publication of this report and any presented images. The Institutional Review Board at Fundación Hospital Nuestra Señora de la Luz IAP reviewed and approved this publication.

\section{Conflict of Interest Statement}

The authors have no conflicts of interest to declare.

\section{Author Contributions}

S.J.A.-L., B.A.-A., A.C.-O., and A.C.P.-O. performed a comprehensive history and oriented ophthalmological exam, obtained informed consent for publication, analyzed and interpreted data regarding fundoscopic and optical coherence tomography findings, and were major contributors in writing the manuscript. C.M.-V. and C.P.-P. reviewed and validated all major case findings and were major contributors in writing the manuscript. All authors read and approved the final manuscript.

\section{References}

1 Shirley MD, Tang H, Gallione CJ, Baugher JD, Frelin LP, Cohen B, et al. Sturge-Weber syndrome and port-wine stains caused by somatic mutation in GNAQ. N Engl J Med. 2013 May;368(21):1971-9.

2 Comi AM. Sturge-Weber syndrome. 1st ed. Vol. 132, Handbook of Clinical Neurology. Elsevier B.V.; 2015. p. 157-68.

3 Higueros E, Roe E, Granell E, Baselga E. Sturge-Weber Syndrome: A Review. Actas Dermosifiliogr. 2017 Jun;108(5):407-17. 


\section{Case Reports in Ophthalmology}

4 Enjolras O, Riche MC, Merland JJ. Facial port-wine stains and Sturge-Weber syndrome. Pediatrics. 1985 Jul;76(1):48-51.

5 Lambiase A, Mantelli F, Bruscolini A, La Cava M, Abdolrahimzadeh S. Ocular manifestations of Sturge-Weber syndrome: pathogenesis, diagnosis, and management. Clin Ophthalmol. 2016;10:871-8.

6 Khokhar S, Pillay G, Sen S, Agarwal E. Clinical spectrum and surgical outcomes in spherophakia: a prospective interventional study [Internet]. Eye (Lond). 2018 Mar;32(3):527-36.

7 Ben Yahia S, Ouechtati F, Jelliti B, Nouira S, Chakroun S, Abdelhak S, et al. Clinical and genetic investigation of isolated microspherophakia in a consanguineous Tunisian family. J Hum Genet. 2009 Sep;54(9):550-3.

8 Mohamed A, Ali MJ, Parel JA, Augusteyn RC, Sangwan VS. In vitro biometry of a human spherophakia [Internet]. Clin Exp Optom. 2017 Mar;100(2):189-91. Available from: http://doi.wiley.com/10.1111/cxo.12439

9 Nelson LB, Maumenee IH. Ectopia lentis [Internet]. Surv Ophthalmol. 1982 Nov-Dec;27(3):143-60. Available from: https://linkinghub.elsevier.com/retrieve/pii/0039625782900698

10 Del-Buano G, Brosi M. A case of Sturge-Weber-Krabbe syndrome with bilateral lens dislocation. G Ital Oftalmol. 1962;15:123.

11 Filatov V, Guyer DR, Lustbader JM, Berkow JW. Dislocation of the crystalline lens in a patient with SturgeWeber syndrome. Ann Ophthalmol. 1992 Jul;24(7):260-2.

12 Chylack LT, Wolfe JK, Singer DM, Leske MC, Bullimore MA, Bailey IL. The Lens Opacities Classification System III. The Longitudinal Study of Cataract Study Group. Arch Ophthalmol. 1993;111:831-6.

13 Rosen AM, Denham DB, Fernandez V, Borja D, Ho A, Manns F, et al. In vitro dimensions and curvatures of human lenses. Vision Res. 2006 Mar;46(6-7):1002-9.

14 Dubbelman M, Van der Heijde GL, Weeber HA. Change in shape of the aging human crystalline lens with accommodation. Vision Res. 2005 Jan;45(1):117-32.

15 Pikkel J, Irena E. Case Report Isolated Spherophakia and Glaucoma. Case Rep Med. 2013;2013:3-5.

16 Chernoff KA, Schaffer JV. Cutaneous and ocular manifestations of neurocutaneous syndromes [Internet]. Clin Dermatol. 2016 Mar-Apr;34(2):183-204.

17 Ram J, Gupta N. Bilateral spontaneous anterior dislocation of crystalline lens in an infant [Internet]. Lancet. 2011 Oct;378(9801):1501.

18 Désir I, Sznajer Y, Depasse F, Roulez F, Schrooyen M, Meire F, et al. LTBP2 null mutations in an autosomal recessive ocular syndrome with megalocornea, spherophakia, and secondary glaucoma [Internet]. Eur J Hum Genet. 2010 Jul;18(7):761-7. Available from: http://www.nature.com/articles/ejhg201011

19 Maumenee AE, Clayman HM, Doughman DJ. Intraocular lens implantation: NIH consensus development conference. I Am Intraocul Implant Soc. 1980 Jan;6(1):21-4. 


\section{Case Reports in Ophthalmology}

\begin{tabular}{l|l}
\hline Case Rep Ophthalmol 2020;11:356-363 \\
\hline DOI: 10.1159/000508064 & $\begin{array}{l}\text { @ 2020 The Author(s). Published by S. Karger AG, Basel } \\
\text { www.karger.com/cop }\end{array}$ \\
\hline
\end{tabular}

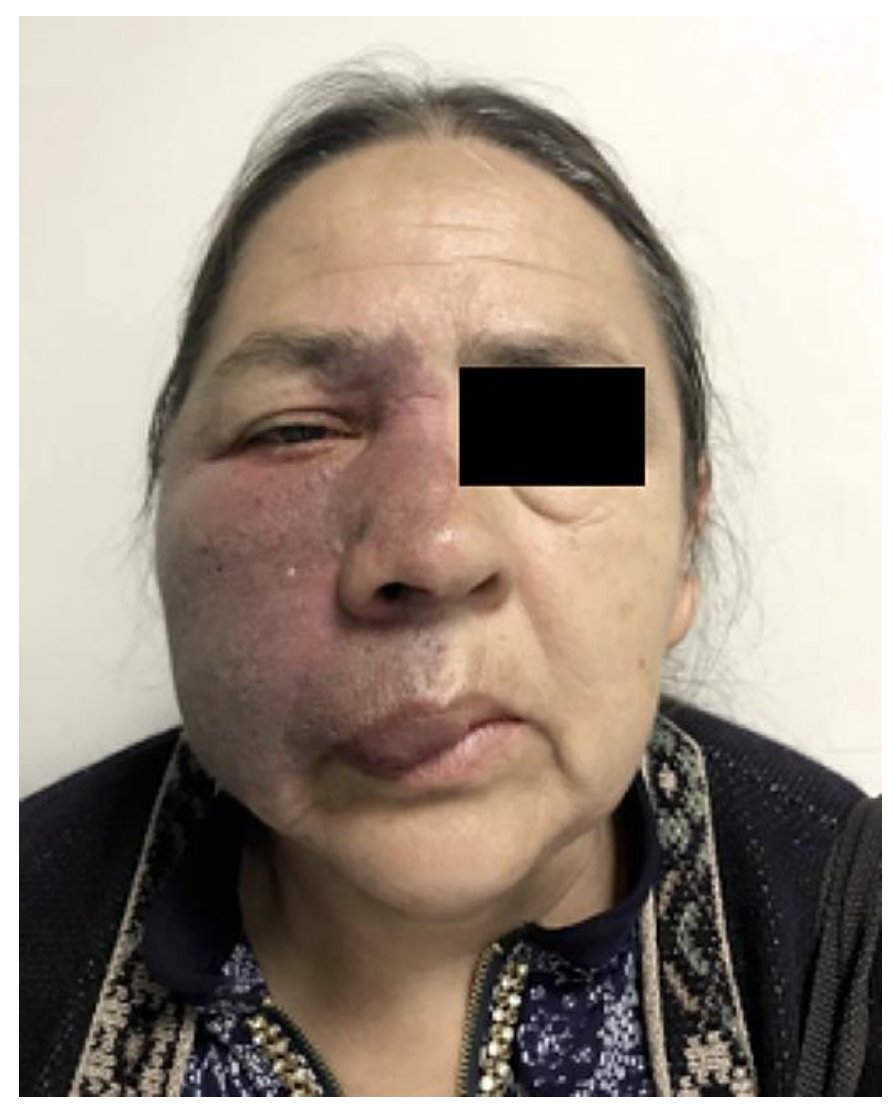

Fig. 1. Port-wine stain in V1 and V1 territory and underlying soft-tissue hypertrophy. 
Case Reports in Ophthalmology
Case Rep Ophthalmol 2020;11:356-363 DOI: $10.1159 / 000508064$

(c) 2020 The Author(s). Published by S. Karger AG, Basel www.karger.com/cop

Avalos-Lara et al.: Spherophakia and Ectopia Lentis in SWS
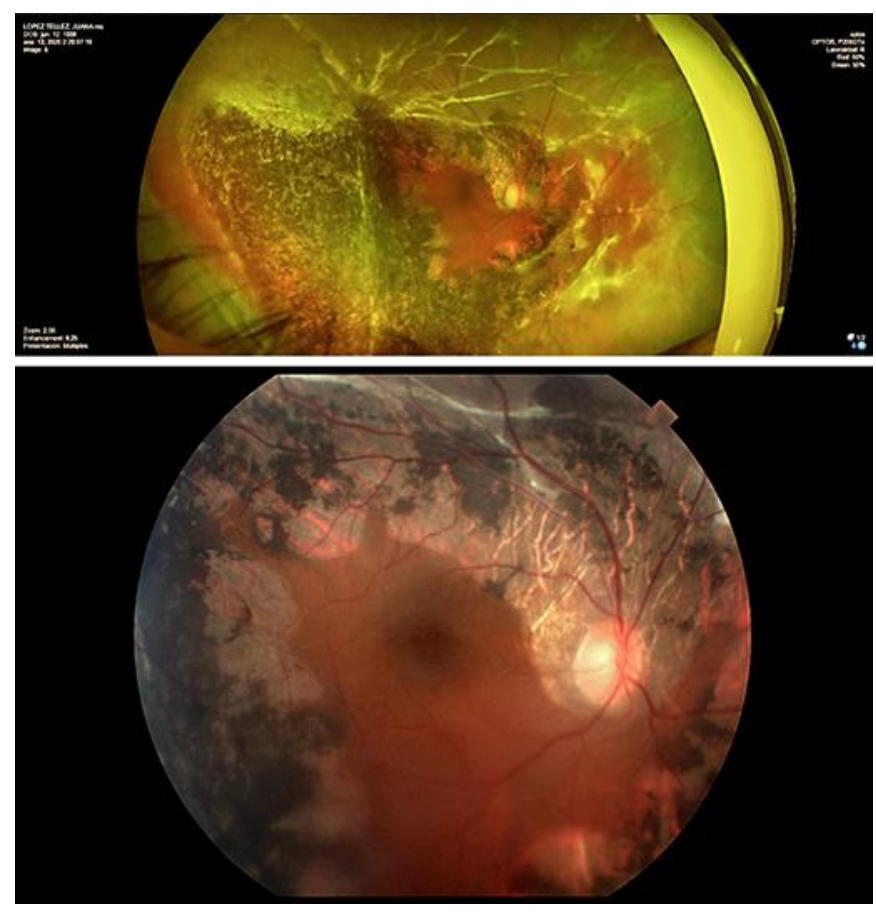

Fig. 2. Fundoscopic OD evaluation. Retinal detachment with proliferative vitreoretinopathy.

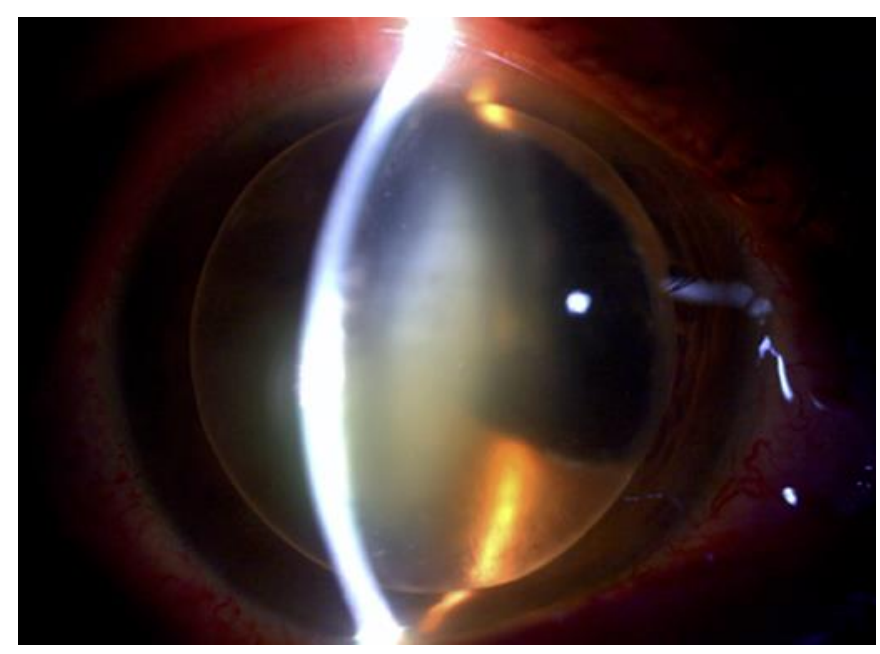

Fig. 3. Slit lamp of the OD evaluation. The lens is luxated anteriorly and opacified. 
Case Reports in Ophthalmology
Case Rep Ophthalmol 2020;11:356-363 DOI: $10.1159 / 000508064$

(c) 2020 The Author(s). Published by S. Karger AG, Basel www.karger.com/cop

Avalos-Lara et al.: Spherophakia and Ectopia Lentis in SWS

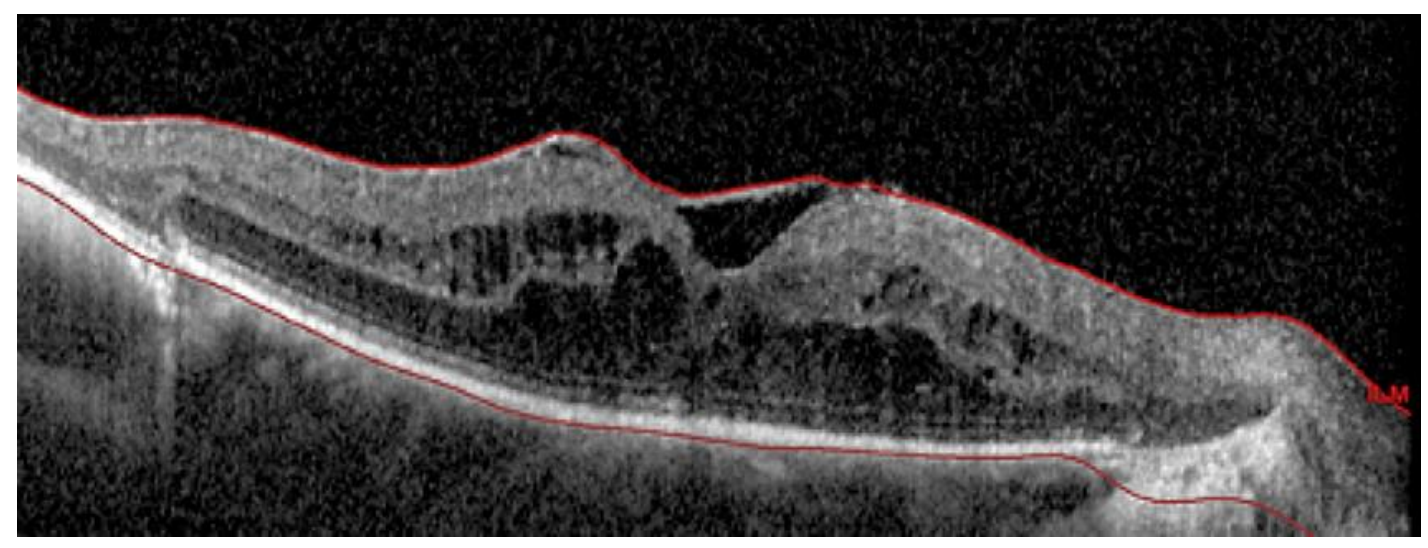

Fig. 4. Optical coherence tomography of the OD showing cystic intraretinal spaces.

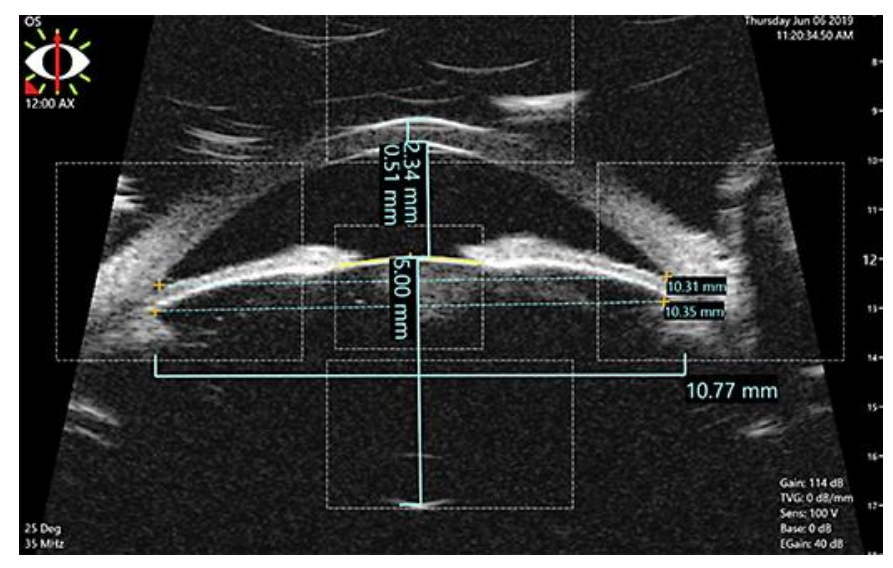

Fig. 5. Ultrasound biomicroscopy OS examination. Normal lens shape. 